\title{
Clinical implications of antitelomeric drugs with respect to the nontelomeric functions of telomerase in cancer
}

This article was published in the following Dove Press journal:

OncoTargets and Therapy

23 August 2013

Number of times this article has been viewed

Jae-il Roh

Young Hoon Sung

Han-Woong Lee

Mouse Molecular Genetics Laboratory, Department of

Biochemistry, Yonsei Laboratory Animal Research Center, Yonsei

University, Seoul, Korea
Correspondence: Han-Woong Lee Mouse Molecular Genetics Laboratory, Department of Biochemistry, Yonsei Laboratory Animal Research Center, Yonsei University, 50 Yonsei-ro, Seoul I20-749, Korea Tel +82 221235698

Emailhwl@yonsei.ac.kr

\begin{abstract}
Telomerase is responsible for maintaining the length of telomeres at the ends of chromosomes. Although most somatic cells do not exhibit telomerase activity, it is reactivated in approximately $85 \%$ of cancers. This simple and attractive phenomenon steers the development of anticancer drugs targeting telomeres and telomerase. Recent studies have been revealing extratelomeric roles of telomerase in normal tissues, affecting processes that are critical for survival and aging of organisms. In this review, we will discuss the current therapeutic strategies targeting telomeres and telomerase and evaluate their potential advantages and risks with respect to nontelomeric functions.
\end{abstract}

Keywords: telomerase, telomere, TERT, TERC, telomerase inhibitors

\section{Introduction}

Telomeres are located at the end of chromosomes (TTAGGG in humans) and vary in length across species (eg, $5-15 \mathrm{~kb}$ in humans, $\sim 48 \mathrm{~kb}$ in mice). During every cell division, telomeres are shortened by $50-200$ bp due to the end replication problem. ${ }^{1,2}$ Therefore, successive replication leads to progressive shortening of telomeres in most somatic cells. Telomerase is a ribonucleoprotein complex comprising two main components: the enzymatic protein subunit telomerase reverse transcriptase (TERT) and a noncoding telomerase RNA component (TERC). ${ }^{3}$ Telomerase elongates telomeres using TERC as a template, thereby maintaining telomere length during cell division. Most somatic cells, however, do not exhibit telomerase activity, and their telomeres shorten with successive rounds of cell division, resulting in critically short telomeres and leading to cellular senescence and apoptosis.

Considering the immortal and proliferative characteristics of cancer cells, short telomeres can have clinical utility in inducing deleterious responses against cancer cells, such as senescence and apoptosis. Furthermore, due to the prevalent reactivation of telomerase in cancer cells, ${ }^{4}$ these cells can be eliminated by stimulating immune responses specific for TERT in patients. These findings are now being actively applied to generate anticancer drugs (Figure 1 and Table 1). Recent advances in this field indicate that telomerase regulates a diverse array of physiological functions other than telomere elongation and alternative spliced variants of telomerase without reverse transcriptase domain are present in normal tissues. ${ }^{5-16}$ By considering these new discoveries, this review will provide a reinterpretation of the current cancer treatments targeting telomeres and telomerase. 


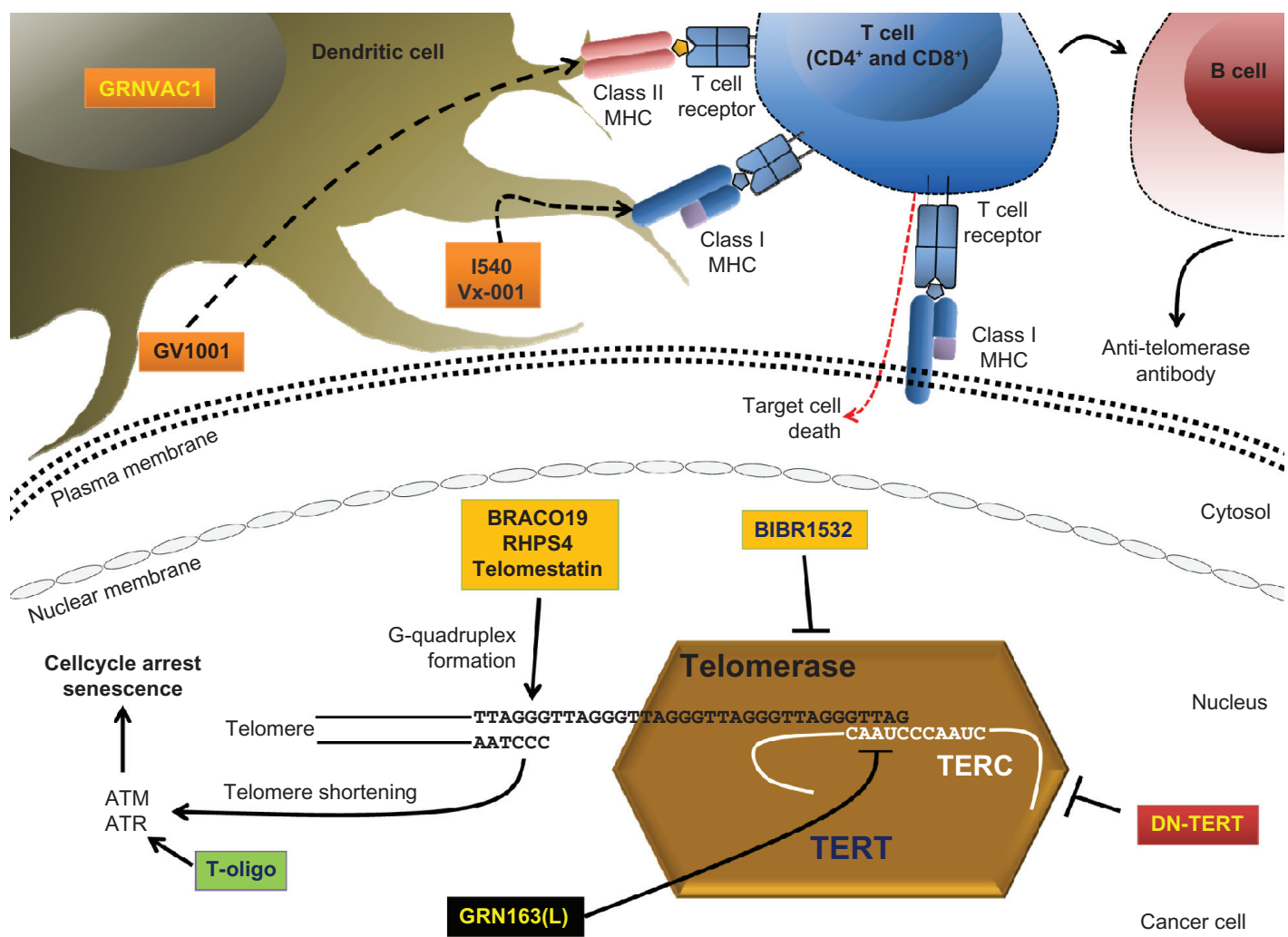

Figure I Drugs targeting telomeres and telomerase.

Notes: Four strategies for targeting telomerase are depicted. GRNI63(L), DN-TERT, and BIBRI532 directly inhibit telomerase. BRACOI9, RHPS4, and telomestatin promote G-quadruplex formation at the end of telomeres. T-oligo mimics dysfunctional telomeres causing ATM/ATR-mediated cell cycle arrest and cellular senescence. Vaccination with peptides derived from TERT or introduction of TERT mRNA into dendritic cells activates T and/or B cells, which recognize and eliminate TERT-expressing cancer cells. Abbreviations: ATM, ataxia telangiectasia mutated; ATR, ATM and Rad3-related; DN-TERT, dominant negative form of telomerase; MHC, major histocompatibility complex; mRNA, messenger RNA; T-oligo, $3^{\prime}$ overhang of telomere sequences; TERC, telomerase RNA component; TERT, telomerase reverse transcriptase.

Table I Drugs targeting telomeres and telomerase

\begin{tabular}{|c|c|c|c|}
\hline Name & Target & Mechanism & Reference \\
\hline GRNI63(L) & TERC & TERC binding & 41 \\
\hline T-oligo & Telomere & $\begin{array}{l}\text { Mimics dysfunctional } \\
\text { telomere }\end{array}$ & 19 \\
\hline DN-hTERT & TERT & TERT degradation & 77,78 \\
\hline BIBRI532 & TERT & $\begin{array}{l}\text { Enzyme inhibitor } \\
\text { of TERT }\end{array}$ & 47 \\
\hline BRACOI9 & Telomere & $\begin{array}{l}\text { G-quadruplex } \\
\text { formation }\end{array}$ & 32,79 \\
\hline RHPS4 & Telomere & $\begin{array}{l}\text { G-quadruplex } \\
\text { formation }\end{array}$ & 80 \\
\hline Telomestatin & Telomere & $\begin{array}{l}\text { G-quadruplex } \\
\text { formation }\end{array}$ & 81 \\
\hline 1540 & HLA-A & $\begin{array}{l}\text { Induction } \\
\text { of immune response }\end{array}$ & 58 \\
\hline$V x-001$ & HLA-A & $\begin{array}{l}\text { Induction } \\
\text { of immune response }\end{array}$ & 60,62 \\
\hline GVI00I & $\begin{array}{l}\text { Multiple } \\
\text { HLA classes }\end{array}$ & $\begin{array}{l}\text { Induction } \\
\text { of immune response }\end{array}$ & 67 \\
\hline GRNVACI & $\begin{array}{l}\text { Dendritic } \\
\text { cell }\end{array}$ & $\begin{array}{l}\text { Vaccination/modified } \\
\text { TERT mRNA }\end{array}$ & 68 \\
\hline
\end{tabular}

Abbreviations: DN-hTERT, dominant negative form of human telomase; HLA-A, human leukocyte antigen A; mRNA, messenger RNA; T-oligo, 3' overhang of telomere sequences; TERC, telomerase RNA component; TERT, telomerase reverse transcriptase.

\section{Drugs targeting telomeres}

In normal cells, short telomeres and telomere dysfunction cause DNA damage responses, resulting in cellular senescence and death through various signals including master regulators of DNA damage such as protein kinases ataxia telangiectasia mutated (ATM) and ATM and Rad3-related (ATR). ${ }^{17,18}$ Likewise, oligonucleotides mimicking the 3' overhang of telomere sequences (T-oligo) cause DNA damage-like responses by inducing a telomere shortening signal, which is similar to the phenotype of functional loss of telomeric repeat-binding factor 2, a telomeric DNA-binding protein. ${ }^{19}$ T-oligo activates ATM, p53, transcription factor $\mathrm{E} 2 \mathrm{~F} 1$, and $\mathrm{p} 95 / \mathrm{NBS} 1$ protein (synthesis phase regulator) ${ }^{20-24}$ rather than suppressing telomerase activity. T-oligo induces apoptosis in melanoma, breast carcinoma, lymphoma, prostate cancer, and fibrosarcoma cell lines but not in normal cells. ${ }^{19,20,25}$ Histone deacetylase inhibitors promote the effect of T-oligo, ${ }^{26}$ suggesting a functional contribution of histone deacetylase to telomeres and/or telomere damage signaling. ${ }^{27}$ As T-oligo does not require telomerase reactivation, it can efficiently target almost all types of cancer cells including 
telomerase-negative cancer cells that maintain their telomeres through alternative lengthening of telomere. ${ }^{28,29}$

As the folding of a telomere to G-quadruplex (G4) prevents telomerase-induced telomere elongation, ${ }^{30,31}$ ligands that induce and stabilize G4 structures can be used as effective drugs against telomerase-positive cancer cells. Among G4-forming small molecules (Table 1), the well-investigated G4 ligand BRACO19 effectively promotes the formation of G4 structures at the end of telomeres. ${ }^{32}$ BRACO19 exhibits low cytotoxicity and efficiently inhibits telomere elongation, resulting in end-to-end chromosomal fusion. ${ }^{33}$ It also induces tumor regression and shows remarkable antitumor activity in vivo. ${ }^{34}$ However, BRACO19 is not currently available for therapeutic trials due to membrane impermeability. In addition, it can be secreted from the cell by ATP-binding cassette transporter superfamily. ${ }^{35}$ Therefore, modifications that increase its membrane permeability and prevent the release of T-oligo might improve the clinical efficacy of BRACO19.

Drugs that mimic or accelerate telomere shortening may exert toxic side effects in highly proliferative tissues. As evidenced by phenotypes of Terc knockout mice in late (G5) generations, short telomeres result in increased programmed cell death (apoptosis) and decreased proliferation in reproductive tissues, spleen, and bone marrow. ${ }^{36}$ Cardiac abnormalities similar to human dilated cardiomyopathy and impaired wound healing are also observed in these mice. ${ }^{31,32}$ Furthermore, short telomeres are carcinogenic, with chromosome end-to-end fusion and aneuploidy apparent in late generations. ${ }^{36}$ As humans have much shorter telomeres than mice, prolonged treatment with antitelomere drugs may be harmful to normal tissues.

\section{Drugs targeting telomerase}

The first generation of Terc and Tert knockout mice are developmentally normal, with short telomere-associated phenotypes observed only in later generations. ${ }^{36}$ As knockdown of Tert or Terc significantly reduces tumor growth, ${ }^{37,38}$ telomerase-targeting drugs may be an alternative to drugs that target telomeres.

For the elongation of telomere length by telomerase, key regions of TERC must be exposed to the surface of telomerase. GRN163 and imetelstat as its lipid (palmitate)conjugated form (GRN163L) contain a short (13-mer) oligonucleotide with $\mathrm{N} 3^{\prime}->\mathrm{P}^{\prime}$ thio-phoshoramidate that binds to the template region of TERC. ${ }^{39} \mathrm{GRN} 163 \mathrm{~L}$ is water soluble, shows high thermal and acid stability, and is resistant to several nucleases. ${ }^{40-42}$ It exerts potent inhibitory effects on telomerase activity in cancer cells. ${ }^{41}$ As GRN163L can penetrate plasma membranes through its lipid conjugation, it does not require additional vehicles for its delivery. ${ }^{39}$ Through intranasal or systemic treatment, both GRN163 and GRN163L can bypass the blood-brain barrier and preferentially affect brain tumor cells with minimum toxicity to normal brain tissue. ${ }^{43,44}$ These studies provide the basis for using both GRN163 and GRN163L as potent drugs against brain tumors, and both have already reached clinical trial stages. Notably, administration of GRN163L reduced the features of cancer stem cells that show multidrug resistance, self-renewal capacity, differentiation, and high metastatic potential. ${ }^{45}$ As MST312, another type of telomerase inhibitor, also exhibits similar effects on cancer stem cells, ${ }^{46}$ telomerase inhibitors may be a prominent candidate targeting cancer stem cells as well.

Small molecule inhibitors against telomerase are likely good candidates for cancer therapy. BIBR1532, a mixed-type, nonnucleosidic inhibitor, is one of the molecules that most potently inhibit telomerase activity. ${ }^{47}$ In germ cell tumor cell lines, simultaneous treatment of BIBR1532 with cisplatin for 300 population doublings reduces telomere length from $18.5 \mathrm{~kb}$ to $8.9 \mathrm{~kb} .{ }^{48}$ However, BIBR1532 does not increase sensitivity to cisplatin, and more prolonged treatment is required to induce the telomere shortening crisis $(1.5-4 \mathrm{~kb}) .{ }^{49}$

Expression of the dominant negative form of telomerase (DN-TERT) causes telomere shortening, apoptosis, and regression of tumor formation. ${ }^{50-52}$ DN-human TERT (DN-hTERT) forms heterodimers with wildtype hTERT that are exported to the cytosol. ${ }^{53}$ As cytosolic hTERT is ubiquitinated by several E3 ubiquitin ligases including MKRN1, CHIP, and HDM2, ${ }^{54-56}$ DN-hTERT causes degradation of wild-type hTERT protein. ${ }^{53}$

Telomerase inhibitors only inhibit the enzymatic activity of telomerase, therefore, strategies to avoid telomereindependent antiapoptotic functions of TERT should be considered. Furthermore, because DN-TERT exerts similar antiapoptotic activity as hTERT, it may promote the survival of cancer cells, especially when wildtype hTERT is depleted. ${ }^{10}$

\section{Immunotherapy for TERT- expressing tumors}

As previously noted, telomerase is frequently activated in cancers. As telomerase-expressing cancer cells may present epitopes of hTERT through human leukocyte antigen, these cells can be eliminated by stimulating the immune system with specific vaccines derived from hTERT. 
Vaccines specific for both classes of human leukocyte antigen have been developed, and at least 25 peptides are known to induce hTERT-specific immune responses. ${ }^{57}$ For example, I540 (ILAKFLHWL) and Vx-001 (9-mer cryptic TERT $_{572}$ peptide) were developed as tumor-associated antigens of hTERT to induce cytotoxic T lymphocyte responses via human leukocyte antigen-A. ${ }^{58-64} \mathrm{GV} 1001$, a 16 amino acid-long peptide of hTERT (611-626), is processed by antigen presenting cells and induces $\mathrm{CD} 4^{+}$or $\mathrm{CD} 8^{+} \mathrm{T}$ cellspecific responses. ${ }^{65-67}$ Vaccination with autologous dendritic cells transfected with hTERT mRNA (GRNVAC1; Geron Corporation, Menlo Park, CA, USA) also triggers $\mathrm{CD} 4^{+}$and $\mathrm{CD} 8^{+} \mathrm{T}$ cell responses in mice and humans. ${ }^{68-70}$ In this case, the lysosomal targeting sequence of lysosome-associated membrane protein-1 is conjugated to enhance peptide processing for antigen presentation. ${ }^{69}$

Although most somatic cells do not exhibit telomerase activity, recent studies indicate that alternative spliced forms of TERT, including those deficient for the reverse transcriptase domain, are expressed in cancer cells and primary tumor tissues, immortalized cells, and even normal tissue, regardless of telomerase activity. ${ }^{14-16}$ The function of alternative-spliced forms of TERT has been poorly investigated in somatic cells. Nevertheless, it is clear that alternative forms of TERT should exert physiological roles. Considering this, overexpression of reverse transcriptase activity-defective TERT can prevent p53-induced apoptosis of the neuronal cells. ${ }^{11}$ Therefore, vaccination against TERT may eliminate critical cell populations expressing full length TERT or its alternative forms, and thus result in unexpected outcomes under specific conditions.

\section{Conclusion}

Although anticancer strategies targeting telomeres and telomerase may be effective, they can also be severely influenced by certain genetic environments. Mutations in p53 are frequently found (approximately $50 \%$ ) in human breast and colorectal adenocarcinomas, ${ }^{71,72}$ and inhibition of TERT leads to cell cycle arrest, senescence, and apoptosis in a p53dependent manner. ${ }^{73,74}$ In a p53-negative cell line, expression of DN-hTERT does not cause apoptosis. ${ }^{75}$ Restoration of $\mathrm{p} 53$, however, sensitizes cancer cells to DN-hTERT, ${ }^{75}$ implying that p53 mutant cancers might be resistant to antitelomerase drugs. A recent study revealed that reexpression of TERT in Tert knockout mice causes aggressive tumor formation and bone metastasis, probably through loss of SMAD4. ${ }^{76}$ This finding demonstrates the risk of virtually imperfect cancer treatment with antitelomerase drugs, which may possibly lead to more aggressive cancers when the patients discontinue treatment. Thus, monitoring SMAD4 mutation status may be helpful for antitelomerase drug therapy. Based on the patient's genotype, additional chemotherapeutics could be coprescribed with telomerase inhibitors. Thus, the clinical application of drugs targeting telomeres and telomerase should be accompanied with, or preceded by, genetic monitoring of the patients.

In spite of their promise, more detailed analyses are required to confirm the safety of anticancer drugs targeting telomeres and telomerase. Prior to clinical trials, the potential risks of the treatments should be evaluated at the level of the entire organism, as accumulating evidence indicates that telomerase has functions other than regulating telomere elongation. In addition, as exemplified by p53 mutations, genetic modifiers affecting clinical outcomes should be prescreened. Moreover, the creation and use of novel mouse models in preclinical studies is essential for the development of anticancer drug strategies that are both effective and safe.

\section{Acknowledgments}

This work was supported by National Research Foundation grants funded by the Ministry of Education, Science and Technology of the Korean government (20120006489, 20120000174, 2012009607) and the Korea Healthcare Technology R\&D Project, Ministry for Health and Welfare Affairs (A085136), Republic of Korea. All authors prepared the manuscript.

\section{Disclosure}

The authors report no conflicts of interest in this work.

\section{References}

1. Huffman KE, Levene SD, Tesmer VM, Shay JW, Wright WE. Telomere shortening is proportional to the size of the G-rich telomeric 3'-overhang. J Biol Chem. 2000;275(26):19719-19722.

2. Harley CB, Futcher AB, Greider CW. Telomeres shorten during ageing of human fibroblasts. Nature. 1990;345(6274):458-460.

3. Greider CW, Blackburn EH. The telomere terminal transferase of Tetrahymena is a ribonucleoprotein enzyme with two kinds of primer specificity. Cell. 1987;51(6):887-898.

4. Kim NW, Piatyszek MA, Prowse KR, et al. Specific association of human telomerase activity with immortal cells and cancer. Science. 1994;266(5193):2011-2015.

5. Hemann MT, Greider CW. Wild-derived inbred mouse strains have short telomeres. Nucleic Acids Res. 2000;28(22):4474-4478.

6. Blasco MA. Telomerase beyond telomeres. Nat Rev Cancer. 2002;2(8): 627-633.

7. Kang HJ, Choi YS, Hong SB, et al. Ectopic expression of the catalytic subunit of telomerase protects against brain injury resulting from ischemia and NMDA-induced neurotoxicity. J Neurosci. 2004;24(6): $1280-1287$. 
8. Rahman R, Latonen L, Wiman KG. hTERT antagonizes p53-induced apoptosis independently of telomerase activity. Oncogene. 2005;24(8): $1320-1327$.

9. Sarin KY, Cheung P, Gilison D, et al. Conditional telomerase induction causes proliferation of hair follicle stem cells. Nature. 2005;436(7053): 1048-1052.

10. Lee J, Sung YH, Cheong C, et al. TERT promotes cellular and organismal survival independently of telomerase activity. Oncogene. 2008;27(26):3754-3760.

11. Choi J, Southworth LK, Sarin KY, et al. TERT promotes epithelial proliferation through transcriptional control of a Myc- and Wnt-related developmental program. PLoS Genet. 2008;4(1):e10.

12. Cong Y, Shay JW. Actions of human telomerase beyond telomeres. Cell Res. 2008;18(7):725-732.

13. Martínez P, Blasco MA. Telomeric and extra-telomeric roles for telomerase and the telomere-binding proteins. Nat Rev Cancer. 2011;11(3):161-176.

14. Yi X, White DM, Aisner DL, Baur JA, Wright WE, Shay JW. An alternate splicing variant of the human telomerase catalytic subunit inhibits telomerase activity. Neoplasia. 2000;2(5):433-440.

15. Saebøe-Larssen S, Fossberg E, Gaudernack G. Characterization of novel alternative splicing sites in human telomerase reverse transcriptase (hTERT): analysis of expression and mutual correlation in mRNA isoforms from normal and tumour tissues. BMC Mol Biol. 2006;7:26.

16. Wong MS, Chen L, Foster C, Kainthla R, Shay JW, Wright WE. Regulation of telomerase alternative splicing: a target for chemotherapy. Cell Rep. 2013;3(4):1028-1035.

17. Deng Y, Chan SS, Chang S. Telomere dysfunction and tumour suppression: the senescence connection. Nat Rev Cancer. 2008;8(6): $450-458$.

18. Sperka T, Wang J, Rudolph KL. DNA damage checkpoints in stem cells, ageing and cancer. Nat Rev Mol Cell Biol. 2012;13(9):579-590.

19. Yaar M, Eller MS, Panova I, et al. Telomeric DNA induces apoptosis and senescence of human breast carcinoma cells. Breast Cancer Res. 2007;9(1):R13.

20. Puri N, Eller MS, Byers HR, Dykstra S, Kubera J, Gilchrest BA. Telomere-based DNA damage responses: a new approach to melanoma. FASEB J. 2004;18(12):1373-1381.

21. Eller MS, Puri N, Hadshiew IM, Venna SS, Gilchrest BA. Induction of apoptosis by telomere $3^{\prime}$ overhang-specific DNA. Exp Cell Res. 2002;276(2):185-193.

22. Eller MS, Li GZ, Firoozabadi R, Puri N, Gilchrest BA. Induction of a p95/Nbs1-mediated S phase checkpoint by telomere 3' overhang specific DNA. FASEB J. 2003;17(2):152-162.

23. Eller MS, Maeda T, Magnoni C, Atwal D, Gilchrest BA. Enhancement of DNA repair in human skin cells by thymidine dinucleotides: evidence for a p53-mediated mammalian SOS response. Proc Natl Acad Sci US A. 1997;94(23):12627-12632.

24. Goukassian DA, Bagheri S, el-Keeb L, Eller MS, Gilchrest BA. DNA oligonucleotide treatment corrects the age-associated decline in DNA repair capacity. FASEB J. 2002;16(7):754-756.

25. Longe HO, Romesser PB, Rankin AM, et al. Telomere homolog oligonucleotides induce apoptosis in malignant but not in normal lymphoid cells: mechanism and therapeutic potential. Int J Cancer. 2009;124(2) 473-482.

26. Sarkar S, Faller DV. T-oligos inhibit growth and induce apoptosis in human ovarian cancer cells. Oligonucleotides. 2011;21(1):47-53.

27. Palacios JA, Herranz D, De Bonis ML, Velasco S, Serrano M, Blasco MA. SIRT1 contributes to telomere maintenance and augments global homologous recombination. J Cell Biol. 2010;191(7):1299-1313.

28. Bryan TM, Englezou A, Gupta J, Bacchetti S, Reddel RR. Telomere elongation in immortal human cells without detectable telomerase activity. EMBO J. 1995;14(17):4240-4248.

29. Bryan TM, Englezou A, Dalla-Pozza L, Dunham MA, Reddel RR. Evidence for an alternative mechanism for maintaining telomere length in human tumors and tumor-derived cell lines. Nat Med. 1997;3(11): 1271-1274.
30. Zahler AM, Williamson JR, Cech TR, Prescott DM. Inhibition of telomerase by G-quartet DNA structures. Nature. 1991;350(6320): 718-720.

31. Wang Q, Liu JQ, Chen Z, et al. G-quadruplex formation at the $3^{\prime}$ end of telomere DNA inhibits its extension by telomerase, polymerase and unwinding by helicase. Nucleic Acids Res. 2011;39(14):6229-6237.

32. Read M, Harrison RJ, Romagnoli B, et al. Structure-based design of selective and potent $\mathrm{G}$ quadruplex-mediated telomerase inhibitors. Proc Natl Acad Sci U S A. 2001;98(9):4844-4849.

33. Incles CM, Schultes CM, Kempski H, Koehler H, Kelland LR, Neidle S. A G-quadruplex telomere targeting agent produces p16-associated senescence and chromosomal fusions in human prostate cancer cells. Mol Cancer Ther. 2004;3(10):1201-1206.

34. Gowan SM, Harrison JR, Patterson L, et al. A G-quadruplex-interactive potent small-molecule inhibitor of telomerase exhibiting in vitro and in vivo antitumor activity. Mol Pharmacol. 2002;61(5):1154-1162.

35. Vasiliou V, Vasiliou K, Nebert DW. Human ATP-binding cassette (ABC) transporter family. Hum Genomics. 2009;3(3):281-290.

36. Blasco MA, Lee HW, Hande MP, et al. Telomere shortening and tumor formation by mouse cells lacking telomerase RNA. Cell. 1997;91(1):25-34.

37. Wang Y, Tao ZZ, Chen SM, Xiao BK, Zhou XH, Liu JP. Application of combination of short hairpin RNA segments for silencing VEGF, TERT and Bcl-xl expression in laryngeal squamous carcinoma. Cancer Biol Ther. 2008;7(6):896-901.

38. Li S, Crothers J, Haqq CM, Blackburn EH. Cellular and gene expression responses involved in the rapid growth inhibition of human cancer cells by RNA interference-mediated depletion of telomerase RNA. J Biol Chem. 2005;280(25):23709-23717.

39. Herbert BS, Gellert GC, Hochreiter A, et al. Lipid modification of GRN163, an N3' - > P5' thio-phosphoramidate oligonucleotide, enhances the potency of telomerase inhibition. Oncogene. 2005;24(33): 5262-5268.

40. Gryaznov S, Pongracz K, Matray T, et al. Telomerase inhibitors oligonucleotide phosphoramidates as potential therapeutic agents. Nucleosides Nucleotides Nucleic Acids. 2001;20(4-7):401-410.

41. Asai A, Oshima Y, Yamamoto Y, et al. A novel telomerase template antagonist (GRN163) as a potential anticancer agent. Cancer Res. 2003;63(14):3931-3939.

42. Herbert BS, Pongracz K, Shay JW, Gryaznov SM, Shea-Herbert B. Oligonucleotide $\mathrm{N} 3^{\prime}->\mathrm{P}^{\prime}$ phosphoramidates as efficient telomerase inhibitors. Oncogene. 2002;21(4):638-642.

43. Marian CO, Cho SK, McEllin BM, et al. The telomerase antagonist, imetelstat, efficiently targets glioblastoma tumor-initiating cells leading to decreased proliferation and tumor growth. Clin Cancer Res. 2010;16(1):154-163.

44. Hashizume R, Ozawa T, Gryaznov SM, et al. New therapeutic approach for brain tumors: Intranasal delivery of telomerase inhibitor GRN163. Neuro-oncology. 2008;10(2):112-120.

45. Joseph I, Tressler R, Bassett E, et al. The telomerase inhibitor imetelstat depletes cancer stem cells in breast and pancreatic cancer cell lines. Cancer Res. 2010;70(22):9494-9504.

46. Serrano D, Bleau AM, Fernandez-Garcia I, et al. Inhibition of telomerase activity preferentially targets aldehyde dehydrogenase-positive cancer stem-like cells in lung cancer. Mol Cancer. 2011;10:96.

47. Pascolo E, Wenz C, Lingner J, et al. Mechanism of human telomerase inhibition by BIBR1532, a synthetic, non-nucleosidic drug candidate. J Biol Chem. 2002;277(18):15566-15572.

48. Mueller S, Hartmann U, Mayer F, et al. Targeting telomerase activity by BIBR1532 as a therapeutic approach in germ cell tumors. Invest New Drugs. 2007;25(6):519-524.

49. Counter CM, Avilion AA, LeFeuvre CE, et al. Telomere shortening associated with chromosome instability is arrested in immortal cells which express telomerase activity. EMBO J. 1992;11(5):1921-1929.

50. Guo C, Geverd D, Liao R, Hamad N, Counter CM, Price DT. Inhibition of telomerase is related to the life span and tumorigenicity of human prostate cancer cells. J Urol. 2001;166(2):694-698. 
51. Zhang R, Wang X, Guo L, Xie H. Growth inhibition of BEL-7404 human hepatoma cells by expression of mutant telomerase reverse transcriptase. Int J Cancer. 2002;97(2):173-179.

52. Misawa M, Tauchi T, Sashida G, et al. Inhibition of human telomerase enhances the effect of chemotherapeutic agents in lung cancer cells. Int J Oncol. 2002;21(5):1087-1092.

53. Nguyen BN, Elmore LW, Holt SE. Mechanism of dominant-negative telomerase function. Cell Cycle. 2009;8(19):3227-3233.

54. Kim JH, Park SM, Kang MR, et al. Ubiquitin ligase MKRN1 modulates telomere length homeostasis through a proteolysis of hTERT. Genes Dev. 2005;19(7):776-781.

55. Lee JH, Khadka P, Baek SH, Chung IK. CHIP promotes human telomerase reverse transcriptase degradation and negatively regulates telomerase activity. J Biol Chem. 2010;285(53):42033-42045.

56. Oh W, Lee EW, Lee D, et al. Hdm2 negatively regulates telomerase activity by functioning as an E3 ligase of hTERT. Oncogene. 2010;29(28):4101-4112.

57. Liu JP, Chen W, Schwarer AP, Li H. Telomerase in cancer immunotherapy. Biochim Biophys Acta. 2010;1805(1):35-42.

58. Vonderheide RH, Hahn WC, Schultze JL, Nadler LM. The telomerase catalytic subunit is a widely expressed tumor-associated antigen recognized by cytotoxic T lymphocytes. Immunity. 1999;10(6):673-679.

59. Domchek SM, Recio A, Mick R, et al. Telomerase-specific T-cell immunity in breast cancer: effect of vaccination on tumor immunosurveillance. Cancer Res. 2007;67(21):10546-10555.

60. Hernandez J, Garcia-Pons F, Lone YC, et al. Identification of a human telomerase reverse transcriptase peptide of low affinity for HLA A2.1 that induces cytotoxic T lymphocytes and mediates lysis of tumor cells. Proc Natl Acad Sci U S A. 2002;99(19):12275-12280.

61. Vetsika EK, Konsolakis G, Aggouraki D, et al. Immunological responses in cancer patients after vaccination with the therapeutic telomerase-specific vaccine Vx-001. Cancer Immunol Immunother. 2012;61(2):157-168.

62. Scardino A, Gross DA, Alves P, et al. HER-2/neu and hTERT cryptic epitopes as novel targets for broad spectrum tumor immunotherapy. J Immunol. 2002;168(11):5900-5906.

63. Vonderheide RH, Domchek SM, Schultze JL, et al. Vaccination of cancer patients against telomerase induces functional antitumor CD8+ T lymphocytes. Clin Cancer Res. 2004;10(3):828-839.

64. Chen DY, Vance BA, Thompson LB, Domchek SM, Vonderheide RH. Differential lysis of tumors by polyclonal $\mathrm{T}$ cell lines and $\mathrm{T}$ cell clones specific for hTERT. Cancer Biol Ther. 2007;6(12):1991-1996.

65. Bernhardt SL, Gjertsen MK, Trachsel S, et al. Telomerase peptide vaccination of patients with non-resectable pancreatic cancer: A dose escalating phase I/II study. Br J Cancer. 2006;95(11):1474-1482.

66. Kyte JA. Cancer vaccination with telomerase peptide GV1001. Expert Opin Investig Drugs. 2009;18(5):687-694.
67. Brunsvig PF, Aamdal S, Gjertsen MK, et al. Telomerase peptide vaccination: a phase I/II study in patients with non-small cell lung cancer. Cancer Immunol Immunother. 2006;55(12):1553-1564.

68. Nair SK, Heiser A, Boczkowski D, et al. Induction of cytotoxic T cell responses and tumor immunity against unrelated tumors using telomerase reverse transcriptase RNA transfected dendritic cells. Nat Med. 2000;6(9):1011-1017.

69. Su Z, Dannull J, Yang BK, et al. Telomerase mRNA-transfected dendritic cells stimulate antigen-specific CD8+ and CD4+ T cell responses in patients with metastatic prostate cancer. $J$ Immunol. 2005;174(6):3798-3807.

70. Su Z, Vieweg J, Weizer AZ, et al. Enhanced induction of telomerasespecific CD4(+) T cells using dendritic cells transfected with RNA encoding a chimeric gene product. Cancer Res. 2002;62(17):5041-5048.

71. Hollstein M, Sidransky D, Vogelstein B, Harris CC. p53 mutations in human cancers. Science. 1991;253(5015):49-53.

72. Greenblatt MS, Bennett WP, Hollstein M, Harris CC. Mutations in the p53 tumor suppressor gene: clues to cancer etiology and molecular pathogenesis. Cancer Res. 1994;54(18):4855-4878.

73. Akeshima R, Kigawa J, Takahashi M, et al. Telomerase activity and p53-dependent apoptosis in ovarian cancer cells. $\mathrm{Br} J$ Cancer. 2001;84(11):1551-1555.

74. Datta A, Bellon M, Sinha-Datta U, et al. Persistent inhibition of telomerase reprograms adult T-cell leukemia to p53-dependent senescence. Blood. 2006;108(3):1021-1029.

75. Brassat U, Balabanov S, Bali D, et al. Functional p53 is required for effective execution of telomerase inhibition in BCR-ABL-positive CML cells. Exp Hematol. 2011;39(1):66-76. e1.

76. Ding $\mathrm{Z}$, Wu CJ, Jaskelioff $\mathrm{M}$, et al. Telomerase reactivation following telomere dysfunction yields murine prostate tumors with bone metastases. Cell. 2012;148(5):896-907.

77. Hahn WC, Stewart SA, Brooks MW, et al. Inhibition of telomerase limits the growth of human cancer cells. Nat Med. 1999;5(10):1164-1170.

78. Zhang X, Mar V, Zhou W, Harrington L, Robinson MO. Telomere shortening and apoptosis in telomerase-inhibited human tumor cells. Genes Dev. 1999;13(18):2388-2399.

79. Harrison RJ, Cuesta J, Chessari G, et al. Trisubstituted acridine derivatives as potent and selective telomerase inhibitors. J Med Chem. 2003;46(21):4463-4476.

80. Leonetti C, Amodei S, D'Angelo C, et al. Biological activity of the G-quadruplex ligand RHPS4 (3,11-difluoro-6,8,13-trimethyl-8Hquino[4,3,2-k1]acridinium methosulfate) is associated with telomere capping alteration. Mol Pharmacol. 2004;66(5):1138-1146.

81. Shin-ya K, Wierzba K, Matsuo K, et al. Telomestatin, a novel telomerase inhibitor from Streptomyces anulatus. J Am Chem Soc. 2001;123(6): $1262-1263$.
OncoTargets and Therapy

\section{Publish your work in this journal}

OncoTargets and Therapy is an international, peer-reviewed, open access journal focusing on the pathological basis of all cancers, potential targets for therapy and treatment protocols employed to improve the management of cancer patients. The journal also focuses on the impact of management programs and new therapeutic agents and protocols on
Dovepress

patient perspectives such as quality of life, adherence and satisfaction. The manuscript management system is completely online and includes a very quick and fair peer-review system, which is all easy to use. Visit http://www.dovepress.com/testimonials.php to read real quotes from published authors. 